\title{
Lack of response to immunotherapy in non-alcoholic steatohepatitis related hepatocellular carcinoma
}

\author{
Masatoshi Kudo \\ Department of Gastroenterology and Hepatology, Kindai University Faculty of Medicine, Osaka-Sayama, Japan \\ Correspondence to: Masatoshi Kudo, MD, PhD. Department of Gastroenterology and Hepatology, Kindai University Faculty of Medicine, 337-2 \\ Ohno-Higashi, Osaka-Sayama, Osaka 589-8511, Japan. Email: m-kudo@med.kindai.ac.jp. \\ Comment on: Pfister D, Núñez NG, Pinyol R, et al. NASH limits anti-tumour surveillance in immunotherapy-treated HCC. Nature 2021;592:450-6.
}

Submitted May 19, 2021. Accepted for publication Jun 03, 2021.

doi: $10.21037 / \mathrm{hbsn}-21-203$

View this article at: https://dx.doi.org/10.21037/hbsn-21-203

The article "NASH limits anti-tumour surveillance in immunotherapy-treated HCC", recently published in Nature, reported that immune checkpoint inhibitors (ICIs) are ineffective against non-alcoholic steatohepatitis (NASH)-related hepatocellular carcinoma (HCC) in NASH-HCC mouse model (1). Normally, $\mathrm{CD} 8^{+} \mathrm{T}$ cells are activated by the recognition of antigens presented on major histocompatibility complex (MHC) class I molecules, transforming into cytotoxic $\mathrm{T}$ cells, which attack cancer by recognizing cancer antigens on the surface of cancer cells via T cell receptors (2). The Nature article showed that the number of ${ }^{+} \mathrm{T}$ cells, specifically, activated $\mathrm{CD} 8^{+}$cells $\left(\mathrm{CD} 8{ }^{+} \mathrm{PD}-1^{+} \mathrm{T}\right.$ cells), increased over time in the NASH mouse model generated by a choline-deficient high fat diet or western-style diet with trans- fat, compared with that in mice fed with a normal diet (control group). Furthermore, the anti-programmed cell death 1 (anti-PD-1) antibody was shown to have no antitumor effect on HCC that appeared in NASH, although it increased the number of $\mathrm{CD} 8^{+} \mathrm{T}$ cells, particularly CD $8^{+} \mathrm{PD}-1^{+} \mathrm{T}$ cells, compared with the control (1).

The investigation of the NASH mouse model showed that the preventive administration of the PD-1 or programmed death-ligand 1 (PD-L1) antibody increases the number of activated $\mathrm{CD} 8^{+} \mathrm{T}$ cells, thereby increasing hepatocarcinogenesis. However, the PD-1/PD-L1 antibody does not reduce the size and number of HCCs that have already developed. Moreover, the anti-PD-1 antibody has the survival-prolonging effect on HCC generated in other hepatocarcinogenesis models, indicating that the attenuation of the effect of the PD-1/PD-L1 antibody is a phenomenon specific to NASH-related HCC. Furthermore, the depletion of $\mathrm{CD} 8^{+} \mathrm{T}$ cells with anti-CD8 antibodies has been shown to reduce the incidence rate of cancer due to the anti-PD-1 antibody. Consequently, this indicates that $\mathrm{CD} 8^{+} \mathrm{T}$ cells were activated because NASH promotes carcinogenesis in NASH-related HCC.

Similarly, single-cell RNA sequencing revealed that activated $\mathrm{CD}^{+} \mathrm{T}$ cells are increased in human HCC. The activation markers, such as TOX and PD-1, are positively correlated in mice and humans and showed that these exhausted markers are also expressed in humans. Thus, a similar phenomenon may occur in humans.

Due to the action of the immune surveillance mechanism by $\mathrm{CD} 8^{+} \mathrm{T}$ cells, cancer cells are usually eliminated by $\mathrm{CD}^{+} \mathrm{T}$ cells that have been presented with antigens in the immune elimination phase (3), except for NASH. However, the lack of this action in $\mathrm{CD}^{+} \mathrm{T}$ cells activated by NASH may increase carcinogenesis. In addition, the lack of response to anti-PD-1 antibody administration may be due to the increase in the number of activated $\mathrm{T}$ cells (that do not recognize antigens) in the immune escape phase. Furthermore, their findings showed that although the administration of the anti-PD-1 antibody to mice induces hepatocyte cell death and fibrosis, the fibrosis is improved by the depletion of $\mathrm{CD}^{+} \mathrm{T}$ cells. Therefore, hepatocyte damage, hepatic fibrosis, and decreased antitumor immunity occurred in NASH due to the expression of special residentlike activated $\mathrm{CD}^{+}$cells (1) (Table 1).

Inada $\mathrm{et} \mathrm{al}$. previously reported a poor immune response of NASH-related HCC to 16 tumor antigen peptides (4). Their experiment against hepatitis B virus (HBV)-HCC in 
Table 1 Role of NASH-specific $\mathrm{CD}^{+} \mathrm{T}$ cell

NASH mouse model

- $\mathrm{CD} 8^{+} \mathrm{PD}-1^{+} \mathrm{T}$ cell is increased over time

- Hepatocyte damage/fibrosis is induced by TNF produced by $\mathrm{CXCR} 6^{+} \mathrm{FOXO} 1^{\text {low }} \mathrm{PD}-1^{\text {high }} \mathrm{CD} 8^{+} \mathrm{T}$ cell

- This resident like T cell is induced by IL-15

- Hepatocyte death is mainly induced by Fas ligand dependent apoptosis

NASH HCC mouse model

- $\mathrm{CD} 8^{+} \mathrm{PD}-1^{+} \mathrm{T}$ cell is increased

- No tumor response to anti-PD-1 Ab

- $\mathrm{HCC}$ is induced by activated $\mathrm{CD} 8^{+} \mathrm{T}$ cell $\left(\mathrm{CXCR} 6^{+} \mathrm{FOXO} 1^{\text {low }} \mathrm{PD}-1^{\text {high }} \mathrm{CD} 8^{+} \mathrm{T}\right.$ cell)

- PD-1 antibody promotes HCC incidence through increased CD8 ${ }^{+} \mathrm{PD}-1^{+} \mathrm{T}$ cell

$\mathrm{NASH}$, non-alcoholic steatohepatitis; PD-1, programmed cell death 1; HCC, hepatocellular carcinoma.

Table 2 Overall survival in NAFLD-HCC $v s$. non NAFLD-HCC: results of 2 validation cohorts

\begin{tabular}{|c|c|c|c|c|c|c|}
\hline OS/patient background & \multicolumn{2}{|c|}{ Cohort $1(n=130)$} & $P$ value & \multicolumn{2}{|c|}{ Cohort $2(n=118)$} & $P$ value \\
\hline OS, months $(95 \% \mathrm{Cl})$ & $5.4(1.8-9.0)$ & $11.0(7.5-14.5)$ & 0.023 & $8.8(3.6-12.4)$ & $17.7(8.8-26.5)$ & 0.034 \\
\hline \multirow[t]{2}{*}{ Country/region } & \multicolumn{2}{|c|}{ Australia, Germany, } & \multicolumn{4}{|c|}{ United States, Europe, } \\
\hline & \multicolumn{2}{|c|}{ Italy, Switzerland } & \multicolumn{4}{|c|}{ Taiwan, Japan } \\
\hline Child-Pugh Class A & $6(46 \%)$ & $76(65 \%)$ & 0.229 & $11(100 \%)$ & 107 (100\%) & \\
\hline Child-Pugh Class B & 7 (54\%) & $41(35 \%)$ & & $0(0 \%)$ & $0(0 \%)$ & \\
\hline MVI & $3(23 \%)$ & 57 (49\%) & 0.079 & $4(36 \%)$ & $30(28 \%)$ & 0.441 \\
\hline EHS & $10(77 \%)$ & $78(67 \%)$ & 0.547 & $6(54 \%)$ & $43(40 \%)$ & 0.233 \\
\hline
\end{tabular}

NAFLD, non-alcoholic fatty liver disease; HCC, hepatocellular carcinoma; NASH, non-alcoholic steatohepatitis; MVI, macrovascular invasion; EHS, extrahepatic spread.

32 patients, hepatitis $\mathrm{C}$ virus (HCV)-HCC in 42 patients, and NASH-HCC in 18 patients showed an immune response of $68.8 \%, 76.2 \%$, and $33.3 \%$, respectively (4). These results were in agreement with the findings of Pfister et al. (published in Nature). Moreover, their data support the findings of the present study.

In the clinical investigation, two validation cohorts were analyzed. The first validation cohort with 130 cases reported a median overall survival (OS) of 5.4 months for non-alcoholic fatty liver disease (NAFLD)-related HCC and 11.0 months for etiologies other than NAFLD. The other validation cohort with 118 cases showed a median OS of 8.8 months for NAFLD-related HCC and 17.7 months for etiologies other than NAFLD. These indicated poor response to the antiPD-1/PD-L1 antibody treatment for NAFLD-related HCC (Table 2). Furthermore, multivariate analysis showed that NAFLD-related HCC was an independent and significant prognostic factor, with a hazard ratio of 2.6 (95\% confidence interval, 1.2-5.6; $\mathrm{P}=0.017$ ) (1). Since NAFLD patients are expected to increase rapidly worldwide, these findings raise critical issues in clinical practice.

Moreover, Dudek et al. [same group of ref. (1)] investigated the activation mechanism of the $\mathrm{CD} 8^{+}$cells in the NASH mouse model (5). They revealed that the unconventionally increased $\mathrm{CD} 8^{+} \mathrm{T}$ cells in the $\mathrm{NASH}$ mouse model are resident-like $\mathrm{CXCR} 6^{+} \mathrm{CD} 8^{+} \mathrm{T}$ cells. The 
resulting phenomenon is that the suppression of FOXO1 expression by interleukin 15 first activates $\mathrm{CXCR}^{+}{ }^{+} \mathrm{CD} 8^{+} \mathrm{T}$ cells, which are completely different from the conventional $\mathrm{CD} 8^{+} \mathrm{T}$ cells activated by recognizing antigens presented on MHC class I molecules. In response to acetate released from steatotic hepatocytes, the $\mathrm{CXCR}^{+} \mathrm{CD}^{+} \mathrm{T}$ cells produce tumor necrosis factor, which causes hepatocyte damage by expressing intercellular adhesion molecule-1 in hepatocytes and adhering activated $\mathrm{CD} 8^{+} \mathrm{T}$ cells to hepatocytes. Furthermore, induced CXCR6 ${ }^{+} \mathrm{CD}^{+} \mathrm{T}$ cells have been shown to cause hepatocyte death via Fas liganddependent apoptosis (5).

Based on these, the decline in immune response or surveillance function reported in the present study is likely an important factor in NAFLD carcinogenesis. This is in addition to the various factors currently considered to be carcinogenic mechanisms of NASH-HCC, including genetic and epigenetic mechanisms, microbiomes, metabolic pathways, molecular signaling pathways, endocrine pathways, and immunological pathways (6-8). Moreover, NAFLD is known to exhibit not only carcinogenesis from liver cirrhosis (9) but also carcinogenesis at a mild stage of fibrosis in approximately $25-50 \%$ of cases (10-12).

However, this article did not clarify the mechanism for increased carcinogenesis due to the administration of the anti-PD-1 antibody in the NASH mouse model and mechanism by which activated $\mathrm{CXCR} 6^{+} \mathrm{CD} 8^{+} \mathrm{T}$ cells promote carcinogenesis, which I hope will be further examined in the future.

The IMbrave150 trial (13) reported hazard ratios of $0.58,0.43$, and 1.05 for HBV-HCC, HCV-HCC, and nonviral HCC, respectively. Thus, the effect of atezolizumab plus bevacizumab appears to be worse for non-viral HCC than for viral-HCC. However, the actual OS is 17.0 and 19.0 months for non-viral HCC in the atezolizumab plus bevacizumab group and HBV-HCC, respectively. Hence, atezolizumab plus bevacizumab is considered to be fully effective for non-viral HCC as a whole. In contrast, the sorafenib group showed OS of 18.1, 12.4, and 12.6 months for non-viral HCC, HBV-HCC, HCV-HCC, respectively. A markedly good OS was observed for the non-viral HCC group; hence, this is possibly the reason for a better OS hazard ratio in the sorafenib group.

As mentioned above, carcinogenesis at a mild fibrosis stage is common in NAFLD (10-12) unlike in viral etiology. Many cases with fairly good conditions are found in the non-viral group, which may be attributed to the good prognosis with molecular target agents (and subsequent treatment). Additionally, it should be noted that non-viral HCC includes many etiologies other than NAFLD, such as alcoholic-related liver disease, autoimmune hepatitis, primary biliary cholangitis, and cryptogenic cirrhosis. Immunotherapy was reported to be ineffective in the NAFLD model; therefore, it is not accurate to conclude that immunotherapy is ineffective in non-viral HCC as a whole. Furthermore, most of patients of the validation cohorts in this study were treated with the PD-1/PD-L1 antibody monotherapy (14). Therefore, conclusions on the effects of combination immunotherapy on NASH-HCC, including atezolizumab plus bevacizumab, (15) must be drawn with sufficient data collected in clinical practice.

The current points of view on the effect of immunotherapy on NASH-HCC are: (I) ICIs may have no effect on pure NASH-HCC, likely because of the decrease in the immune response of $\mathrm{CD} 8^{+} \mathrm{T}$ cells to tumor antigens and absence of immune surveillance mechanism. (II) Although Pfister et al. (article published in Nature) examined this point from various angles, it did not clarify the presence or absence of the effect of combination immunotherapy, which needs further examination. (III) NASH-HCC based solely on clinical diagnosis may not be pure NASH-HCC because a definite diagnosis of NASH-HCC is challenging without pathological diagnosis. (IV) Clinical diagnosis of NASH-HCC alone and not administering atezolizumab plus bevacizumab may be disadvantageous to the patients. Therefore, it is important to initiate treatment with atezolizumab plus bevacizumab and switch to second-line treatment immediately after it is found ineffective. In this regard, it is essential to keep in mind that NAFLD-related HCC may have a lack of response to immunotherapy at the start of treatment.

\section{Acknowledgments}

Funding: None.

\section{Footnote}

Provenance and Peer Review: This article was commissioned by the editorial office of Hepatobiliary Surgery and Nutrition. The article did not undergo external peer review.

Conflicts of Interest: The author has completed the ICMJE uniform disclosure form (available at https://hbsn. amegroups.com/article/view/10.21037/hbsn-21-203/coif). The author reports consulting fees from BMS, Eisai, MSD, 
Ono Pharmaceuticals, Roche, payment or honoraria from Bayer, Eisai, MSD, BMS, EA Pharma, Eli Lilly, Chugai, and research funding for institution from Eisai, Takeda, Otsuka, Taiho, EA Pharma, Gilead Sciences, Abbvie, Sumitomo Dainippon Pharma, Chugai, Ono Pharmaceutial Co.

Ethical Statement: The author is accountable for all aspects of the work in ensuring that questions related to the accuracy or integrity of any part of the work are appropriately investigated and resolved.

Open Access Statement: This is an Open Access article distributed in accordance with the Creative Commons Attribution-NonCommercial-NoDerivs 4.0 International License (CC BY-NC-ND 4.0), which permits the noncommercial replication and distribution of the article with the strict proviso that no changes or edits are made and the original work is properly cited (including links to both the formal publication through the relevant DOI and the license). See: https://creativecommons.org/licenses/by-nc-nd/4.0/.

\section{References}

1. Pfister D, Núñez NG, Pinyol R, et al. NASH limits antitumour surveillance in immunotherapy-treated HCC. Nature 2021;592:450-6.

2. Nishida N, Sakai K, Morita M, et al. Association between Genetic and Immunological Background of Hepatocellular Carcinoma and Expression of Programmed Cell Death-1. Liver Cancer 2020;9:426-39.

3. Dunn GP, Bruce AT, Ikeda H, Old LJ, Schreiber RD. Cancer immunoediting: from immunosurveillance to tumor escape. Nat Immunol 2002;3:991-8.

4. Inada Y, Mizukoshi E, Seike T, et al. Characteristics of Immune Response to Tumor-Associated Antigens and Immune Cell Profile in Patients With Hepatocellular Carcinoma. Hepatology 2019;69:653-65.

Cite this article as: Kudo M. Lack of response to immunotherapy in non-alcoholic steatohepatitis related hepatocellular carcinoma. HepatoBiliary Surg Nutr 2021;10(4):522-525. doi: 10.21037/hbsn-21-203
5. Dudek M, Pfister D, Donakonda S, et al. Auto-aggressive CXCR6+ CD8 T cells cause liver immune pathology in NASH. Nature 2021;592:444-9.

6. Wolf MJ, Adili A, Piotrowitz K, et al. Metabolic activation of intrahepatic CD8+ T cells and NKT cells causes nonalcoholic steatohepatitis and liver cancer via cross-talk with hepatocytes. Cancer Cell 2014;26:549-64.

7. Nahon P, Allaire M, Nault JC, et al. Characterizing the mechanism behind the progression of NAFLD to hepatocellular carcinoma. Hepat Oncol 2020;7:HEP36.

8. Geh D, Anstee QM, Reeves HL. NAFLD-Associated HCC: Progress and Opportunities. J Hepatocell Carcinoma 2021;8:223-39.

9. Kudo M. Hepatocellular carcinoma and NASH. J Gastroenterol 2004;39:409-11.

10. Mittal S, El-Serag HB, Sada YH, et al. Hepatocellular Carcinoma in the Absence of Cirrhosis in United States Veterans is Associated With Nonalcoholic Fatty Liver Disease. Clin Gastroenterol Hepatol 2016;14:124-31.e1.

11. Piscaglia F, Svegliati-Baroni G, Barchetti A, et al. Clinical patterns of hepatocellular carcinoma in nonalcoholic fatty liver disease: A multicenter prospective study. Hepatology 2016;63:827-38.

12. Stine JG, Wentworth BJ, Zimmet A, et al. Systematic review with meta-analysis: risk of hepatocellular carcinoma in non-alcoholic steatohepatitis without cirrhosis compared to other liver diseases. Aliment Pharmacol Ther 2018;48:696-703.

13. Finn RS, Qin S, Ikeda M, et al. Atezolizumab plus Bevacizumab in Unresectable Hepatocellular Carcinoma. N Engl J Med 2020;382:1894-905.

14. Kudo M. Limited Impact of Anti-PD-1/PD-L1 Monotherapy for Hepatocellular Carcinoma. Liver Cancer 2020;9:629-39.

15. Kudo M. Combination Cancer Immunotherapy with Molecular Targeted Agents/Anti-CTLA-4 Antibody for Hepatocellular Carcinoma. Liver Cancer 2019;8:1-11. 